\title{
Expression of CD200 and CD200R regulatory molecules on the CD83 + monocyte-derived dendritic cells generated from patients with laryngeal cancer
}

\author{
Janusz Klatka ${ }^{1}$, Ewelina Grywalska ${ }^{2}$, Maria Klatka ${ }^{3}$, \\ Mansur Rahnama ${ }^{4}$, Agnieszka Polak ${ }^{2}$, Jacek Rolinski ${ }^{2}$
}

${ }^{1}$ Department of Otolaryngology and Laryngeal Oncology, Medical University of Lublin, Lublin, Poland ${ }^{2}$ Department of Clinical Immunology and Immunotherapy, Medical University of Lublin, Lublin, Poland

${ }^{3}$ Department of Pediatric Endocrinology and Diabetology, Medical University of Lublin, Lublin, Poland

${ }^{4}$ Department of Oral Surgery, Medical University of Lublin, Lublin, Poland

\begin{abstract}
CD200 molecule may play a role in local tumor invasion and augmenting the metastatic capacity of squamous cell carcinoma. The objective of the study was to assess by means of flow cytometry the expression of CD200 and its receptor, CD200R, on CD83 + monocyte-derived dendritic cells (Mo-DCs), pulsed or not with autologous tumor cell lysates (aTCL) in patients who suffer from laryngeal carcinoma in comparison to healthy donors. The median value of CD200 mean fluorescence intensity (MFI) on the Mo-DCs pulsed with aTCL of the patients with laryngeal cancer was 61.94 and was statistically significantly higher than on the unpulsed Mo-DCs of these patients (24.81) and healthy donors (16.63), $p=0.0034$ and $p=0.0004$, respectively. Median MFI score of CD200R in specimen derived from patients with laryngeal cancer was 259.31 on Mo-DCs pulsed with aTCL, while in unpulsed Mo-DCs was $86.74(p=0.0035)$ and on the Mo-DCs from control group it was $67.51(p=0.0004)$. The obtained results showed a relation between the presence of laryngeal cancer and the expression of CD200 and CD200R molecules on the CD83 + Mo-DCs pulsed with autologous cancer cell lysates. This analysis may have implications for setting new therapeutic options for cancer immunotherapy in the future. (Folia Histochemica et Cytobiologica 2013, Vol. 51, No. 1, 59-65)
\end{abstract}

Key words: CD200, CD200R, monocyte-derived dendritic cells, cell lysates, laryngeal cancer

\section{Introduction}

CD200 (formerly OX2) is a type 1a membrane protein with two extracellular Ig superfamily domains, a single transmembrane region, and a short cytoplasmic tail [1, 2], broadly expressed on a variety of cell types, such as some dendritic cells, thymocytes, $\mathrm{T}$ and $\mathrm{B}$ lymphocytes, neurons, kidney glomeruli, syncytiotrophoblasts, and endothelial cells [3]. CD200 delivers immunoregulatory signals by binding to receptors expressed on monocytes/myeloid cells, including monocyte-derived den-

Correspondence address: J. Klatka, Department of Otolaryngology and Laryngeal Oncology, Medical University of Lublin; Jaczewskiego St. 8, 20-954 Lublin, Poland; tel.: +48 8175648 40; fax: +48 8175648 40;

e-mail: janusz.klatka@wp.pl dritic cells, and T lymphocytes. Signals delivered via the CD200:CD200R axis were shown to play an important role in the regulation of anti-tumor immunity. Overexpression of CD200 was found in a number of malignancies and on cancer stem cells [4] and it was assumed that this molecule may play roles in local tumor invasion as well as augmenting the metastatic capacity of squamous cell carcinoma [5].

Laryngeal cancer is one of the most commonly occurring malicious cancers of head and neck region, with squamous cell carcinoma as the predominant histologic type [6, 7]. Despite constant development, the classical therapeutic methods, such as surgical procedures or radiotherapy are not sufficiently effective in prolonging the survival time of cancer patients and improving the quality of their lives [8]. Therefore, the increasing morbidity and unsatisfactory ef- 
fects of treatment, especially in cases of advanced laryngeal carcinoma, stimulate scientists and clinicians to develop more effective therapy modalities including immunotherapy with the use of the dendritic cells and/or monoclonal antibodies [9].

The main aim of the present study was to assess the expression of CD200 and CD200R on CD83+ monocyte-derived dendritic cells, pulsed or not with autologous tumor cell lysates, of patients who suffer from laryngeal cancer in comparison to healthy donors. To the best of our knowledge, the present publication is the first to describe the mentioned issue. The results of our study may have implications for setting new standards for cancer immunotherapy in the future.

\section{Material and methods}

Patients and healthy controls. Forty-four male patients treated surgically for primarily diagnosed squamous cell carcinoma of the larynx, without preoperative treatment, were included in the study. The diagnosis of squamous cell carcinoma of the larynx was established by histopathology of tumor samples. The mean age of patients was $63.23 \pm$ 8.85 years (ranging from 47 to 76 years; median: 64.5 ). Table I presents patients' characteristics.

Peripheral blood from twelve healthy male donors, at the mean age of $56.83 \pm 10.24$ (ranging from 43 to 70 years; median: 57), was used as a control. Both in patients and healthy donors peripheral blood WBC was within the normal range between 4 and $10 \mathrm{G} / \mathrm{L}$.

None of the patients and controls showed signs of infection at the time of investigation and for a month before surgery none had been taking drugs of known influence on the immune system. None of the patients or healthy donors had undergone blood transfusion. Persons with allergic diseases in anamnesis were excluded from the study. The research protocol was approved by the local Ethics Committee and all patients gave written informed consent.

Isolation of the peripheral blood mononuclear cells. Mononuclear cells (PBMCs) were separated from heparinized venous blood of the patients and the healthy donors by density gradient centrifugation using Gradisol-L (Aqua Medica, Poland) and centrifuged for 20 minutes at $700 \mathrm{~g}$. PB$\mathrm{MCs}$ were collected and washed twice in PBS without $\mathrm{Ca} 2+$ or $\mathrm{Mg} 2+$ (Biochrom, Germany). Interphase cells were washed twice in phosphate-buffered saline (PBS) without $\mathrm{Ca} 2+$ or $\mathrm{Mg} 2+$ (Biochrom AG, Germany) and then resuspended at $0.5-1 \times 10^{6}$ cells $/ \mathrm{mL}$. Cell viability was checked by Trypan Blue exclusion test (Sigma-Aldrich, Germany).

Preparation of the neoplastic cell lysates. Laryngeal cancer tissue was obtained during surgical treatment. Tumor samples (without necrotic areas) were digested with $1 \mathrm{mg} / \mathrm{mL}$ of type I collagenase (Biochrome AG, Germany), $1 \mathrm{mg} / \mathrm{mL}$ of type I deoxyribonuclease (Sigma-Aldrich, Germany) and $0.1 \mathrm{mg} / \mathrm{mL}$ of hyaluronidase (Sigma-Aldrich, Germany) and washed twice in RPMI 1640 (Biochrom, Germany). Tumor cells were homogenized by five repeated cycles of quick freezing $\left(-80^{\circ} \mathrm{C}\right)$ and thawing $\left(37^{\circ} \mathrm{C}\right)$. Large particles were removed by centrifugation and after that supernatants were passed through a $20 \mu \mathrm{m}$ pore filter.

Dendritic cells generation. PBMCs were incubated with antiCD14 microbeads (Miltenyi-Biotec, Germany) and passed through MACS separation columns according to the manufacturer's instructions. Viability of isolated cells was confirmed using Trypan Blue dye exclusion and samples with viability less than $90 \%$ were excluded from analysis. The CD14 positive cell population was used to prepare monocyte-derived dendritic cells (Mo-DCs). After isolation, the CD14+ cells were washed twice with phosphate-buffered saline (PBS) and seeded into cell culture flasks. The CD14+ cells were cultured in RPMI 1640 medium (BioWhittaker, USA) supplemented with $2 \%$ human albumin (Baxter, Austria), $100 \mathrm{IU} / \mathrm{mL}$ penicillin, $50 \mathrm{mg} / \mathrm{mL}$ streptomycin and $100 \mathrm{mg} / \mathrm{mL}$ neomycin (Sigma-Aldrich, Germany) for $2 \mathrm{~h}$ at $37^{\circ} \mathrm{C}$ and $5 \% \mathrm{CO} 2$. After incubation, the non-adherent cells were removed with PBS without $\mathrm{Ca} 2+$ and $\mathrm{Mg} 2+$ (Biochrom, Germany). Adherent cells were grown in the appropriate culture medium for 7 days. On days 1, 3 and $51000 \mathrm{IU} / \mathrm{mL}$ rhGM-CSF (Leukine, USA) and $500 \mathrm{IU} / \mathrm{mL}$ rhIL-4 (Miltenyi-Biotec, Germany) were added to the cultures. The cells were then divided into two equal parts and the first part was assessed using flow cytometry method without stimulation with tumor cell lysates. Tumor necrosis factor $\alpha$ (rhTNF- $\alpha$, Strathmann, Germany) at a concentration of $50 \mathrm{ng} / \mathrm{mL}$ and the autologous tumor cell lysates were added to the second part of cells during the last 48 hours of culture for the maturation and pulsing of the Mo-DCs.

The Mo-DCs of healthy controls were generated as described above; however, they were not pulsed with autologous tumor cell lysates due to the absence of cancer tissue in this group. Generated cells were then harvested using Trypsin/EDTA solution (Biochrom, Germany).

Flow cytometric analysis. Following monoclonal antibodies (mAb) were used: anti-CD83 FITC (BD Bioscience, USA)/anti-CD200 PE (AbD Serotec, USA) and anti-CD83 FITC (BD Bioscience, USA)/anti-CD200R PE (AbD Serotec, USA). The cell phenotype characterization was performed using a FACSCalibur cytometer equipped with 488$\mathrm{nm}$ argon laser (Becton Dickinson, USA) and analyzed with CellQuest Software (Becton Dickinson, USA). We collected 300000 of events in total. Cell debris and dead cells were excluded from the analysis based on scatter signal.

Statistical analysis. Statistica 9 PL (Stat Soft Inc.) software was applied to statistical analysis and Mann-Whitney U test was used. Pearson's linear correlation coefficient (r) was 

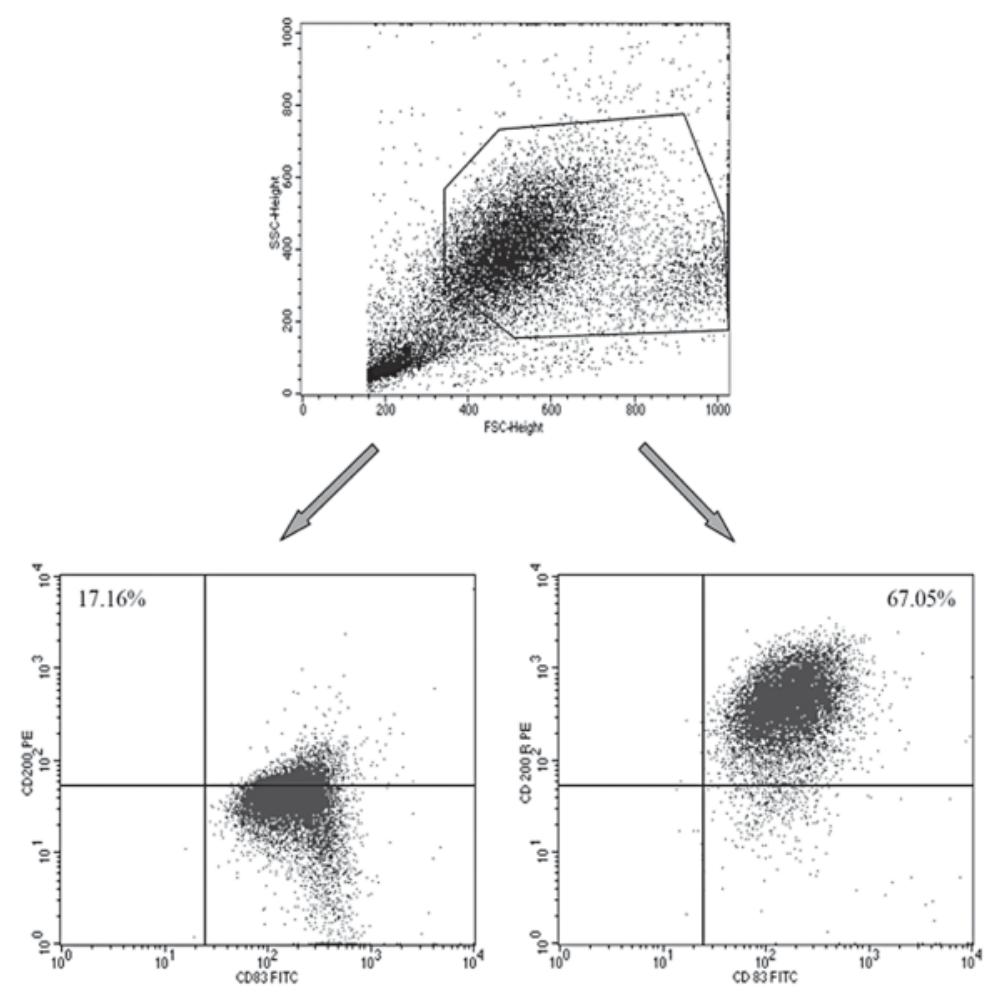

Figure 1. An example of a three-color flow cytometry analysis of a CD200 and CD200R molecules expression on the MoDCs generated from a patient with squamous cell carcinoma of the larynx. The upper dot plot shows the forward scatter/ /side scatter (FSC/SSC) distribution and the gate used to select Mo-DCs for analysis. The number in the upper right quadrant in the dot plots represents the percentage of CD83+CD200+ cells (down left dot plot) and the percentage of CD83 + CD200R + cells (down right dot plot)

calculated to disclose relationships between variables. All results are showed as means \pm standard deviation $(\mathrm{SD})$ and medians. P-value less than 0.05 was considered statistically significant.

\section{Results}

The results are presented in the form of percentage values of the cells with the expression of a given antigen and the mean fluorescence intensity (MFI), which is the mean score of the density of an expression of a given molecule on a cell. Figure 1 presents an example of a three-color flow cytometry analysis of an expression of CD200 and CD200R molecules on the CD83 + Mo-DCs generated from patients with squamous cell carcinoma of the larynx.

Our study revealed that the percentage of monocyte-derived DCs with an expression of CD83 antigen in patients (median: 90.54\%, range 51.45-99.22\%; mean: $86.44 \pm 12.18 \%$ ) was statistically lower $(\mathrm{p}=0.0002)$ than in healthy donors (median $99.79 \%$, range 99.66-99.86\%; mean: $99.79 \pm 0.07 \%$ ). The differences of CD83 MFI values between the patients' and control groups were also statistically significant $(\mathrm{p}=0.04)$; higher in patients (median: 287.49, range 213.96-628.26; mean: $334.34 \pm 117.28)$ than in healthy individuals (median: 224.07, range 139.72-276.38; mean: $212.71 \pm 63.41)$.

The median MFI value of CD200 antigen on the CD83+ Mo-DCs from laryngeal cancer patients, stimulated with autologous tumor cell lysates, was 61.94 (range 41.65-.37; mean: $111.29 \pm 95.44$ ) and was statistically significantly higher than on the unpulsed MoDCs of laryngeal cancer patients (median: 24.81; range 18.73-49.37; mean: $26.54 \pm 8.62$ ) and healthy donors (median: 16.63, range 14.4-.47; mean: $17.99 \pm 4.15$ ), $\mathrm{p}=0.0034$ and $\mathrm{p}=0.0004$, respectively (Figure 2).

MFI of CD200 receptor expression on CD83+ Mo-DCs among the patients with laryngeal cancer was $395.54 \pm 215.89$ (median: 259.31 , range 188.63$-810.35)$, while in the control group it was $71.18 \pm$ \pm 37.12 (median: 67.51, range 16.99-124.78). Surprisingly, Mann-Whitney U test revealed that the statistical significance was exactly the same as in the case of the CD200 MFI assessment $(p=0.0004)$. Median MFI score of CD200R among the unpulsed Mo-DCs 


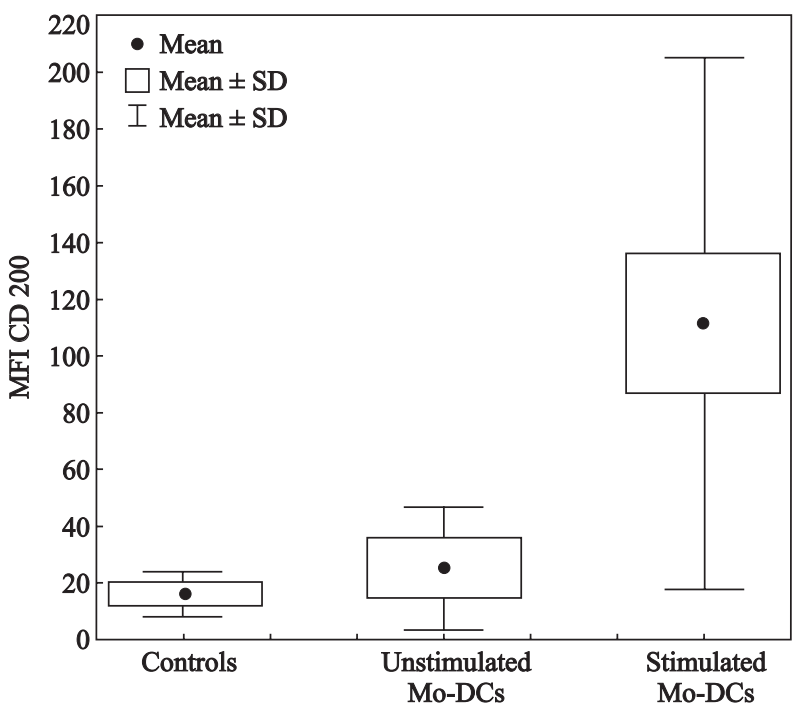

Figure 2. A diagram presenting the differences in the MFI values of CD200 marker expression on CD83+ monocytederived DCs stimulated or not stimulated with autologous cancer cell lysates in patients with laryngeal cancer and in control group (Mo-DCs not stimulated)

derived from persons with laryngeal cancer was $96.74 \pm$ \pm 49.18 (median: 89.23, range 8.64-171.42) and was significantly different from those pulsed with autologous cancer cell lysates $(\mathrm{p}=0.0035)$ (Figure 3$)$.

The proportion of CD83+CD200+ cells in the blood of laryngeal cancer patients was higher than in healthy persons (median: $11.63 \%$, range $6.17 \%-$ $-39.75 \%$; mean: $13.12 \pm 8.75 \%$ vs. median: $9.34 \%$, range 6.12-.68\%; mean: $11.35 \pm 6.19 \%$, respectively), however, the difference was statistically not significant $(\mathrm{p}=0.64)$. The control group was characterized by a slightly higher percentage value of CD83+ Mo-DCs with CD200R antigen expression (median: $73.22 \%$, range $36.2-89.05 \%$; mean: $70.24 \pm 19.49 \%$ ) than laryngeal cancer patients (median: $68.64 \%$, range $29.03-88.82 \%$; mean: $64.28 \pm 18.95 \%$ ), however, the difference was not statistically significant $(\mathrm{p}=0.58)$.

No correlations were found between the measured characteristics of cells and clinicopathological data, presented in Table 1.

\section{Discussion}

Our study revealed that there is a significant relationship between the presence of laryngeal cancer and the expression of CD200 and CD200R molecules on the monocyte-derived dendritic cells pulsed with autologous cancer cell lysates. Unstimulated CD83+ Mo-DCs of healthy controls and patients with laryngeal cancer presented significantly lower MFI values

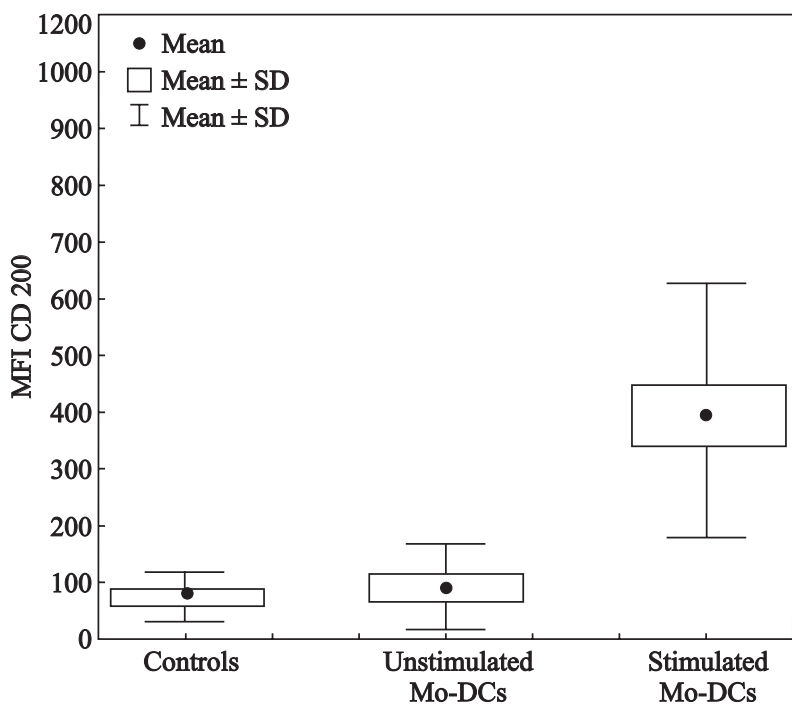

Figure 3. A diagram presenting the differences in the MFI values of CD200R antigen expression on CD83+ monocyte-derived DCs stimulated or not with autologous cancer cell lysates in patients with laryngeal cancer and in control group (CD83+ Mo-DCs not stimulated)

of CD200 and CD200R antigen expression than the same type of cells after the stimulation. This finding means that pulsing DCs with laryngeal cancer tumor lysates would increase the known inhibitory effect of the CD200 molecule on myeloid cells and we assess this finding as a surprising one. Many studies published before $[10,11]$ used the concept of pulsing DCs with autologous tumor lysates to elicit an effective antitumor immune response.

The expression of CD200 was implicated in multiple types of human cancer including squamous cell carcinoma. However, the impact of tumor expression of CD200 on tumor immunity remains poorly understood and the expression of the discussed molecules on the Mo-DCs of laryngeal cancer patients has not been assessed before.

Wang et al. [12] generated CD200-positive mouse plasmacytoma J558 and mastocytoma P815 cells and found that CD200-positive tumors were often completely rejected by adoptively transferred cytotoxic $\mathrm{T}$ lymphocytes (CTL) without tumor recurrence. The same authors [12] also proved that CD200-negative tumors were initially rejected by adoptively transferred CTL; however, the majority of tumors recurred. Tumor expression of CD200 significantly inhibited suppressive activity and IL-10 production by tumorassociated myeloid cells (TAMC). Neutralization of IL-10 significantly inhibited the suppressor activity of TAMC, and IL-10-deficiency allowed TAMC to kill cancer cells. Thus, tumor expression of CD200 
Table 1. Patient characteristics

\begin{tabular}{|c|c|c|c|}
\hline \multicolumn{3}{|c|}{ Total number of patients } & \multirow{2}{*}{$\begin{array}{c}44 \\
63.23 \pm 8.85 \\
64.5\end{array}$} \\
\hline & $\begin{array}{c}\text { Age } \\
\text { (years) }\end{array}$ & & \\
\hline \multirow[t]{3}{*}{$\begin{array}{l}\text { Grading (Histological differentiation } \\
\text { of surgically resected tumour) }\end{array}$} & G1 & $\begin{array}{l}\text { Number of patients } \\
\text { Percentage }\end{array}$ & $\begin{array}{c}12 \\
27.27\end{array}$ \\
\hline & $\mathrm{G} 2$ & $\begin{array}{c}\text { Number of patients } \\
\text { Percentage }\end{array}$ & $\begin{array}{c}19 \\
43.18\end{array}$ \\
\hline & G3 & $\begin{array}{c}\text { Number of patients } \\
\text { Percentage }\end{array}$ & $\begin{array}{c}13 \\
29.55\end{array}$ \\
\hline \multirow[t]{4}{*}{$\begin{array}{l}\mathrm{T} \text { classification (The size of the tumour } \\
\text { and whether it has invaded nearby tissue) }\end{array}$} & $\mathrm{T} 1$ & $\begin{array}{l}\text { Number of patients } \\
\text { Percentage }\end{array}$ & $\begin{array}{c}7 \\
15.91\end{array}$ \\
\hline & $\mathrm{T} 2$ & $\begin{array}{l}\text { Number of patients } \\
\text { Percentage }\end{array}$ & $\begin{array}{c}9 \\
20.45\end{array}$ \\
\hline & $\mathrm{T} 3$ & $\begin{array}{c}\text { Number of patients } \\
\text { Percentage }\end{array}$ & $\begin{array}{c}16 \\
36.36\end{array}$ \\
\hline & $\mathrm{T} 4$ & $\begin{array}{c}\text { Number of patients } \\
\text { Percentage }\end{array}$ & $\begin{array}{c}12 \\
27.27\end{array}$ \\
\hline \multirow[t]{2}{*}{ Distant metastasis } & Yes & $\begin{array}{c}\text { Number of patients } \\
\text { Percentage }\end{array}$ & $\begin{array}{l}0 \\
0\end{array}$ \\
\hline & No & $\begin{array}{c}\text { Number of patients } \\
\text { Percentage }\end{array}$ & $\begin{array}{c}44 \\
100\end{array}$ \\
\hline \multirow[t]{3}{*}{ Site of tumour } & Supraglottic & $\begin{array}{c}\text { Number of patients } \\
\text { Percentage }\end{array}$ & $\begin{array}{c}20 \\
45.45\end{array}$ \\
\hline & Glottic & $\begin{array}{c}\text { Number of patients } \\
\text { Percentage }\end{array}$ & $\begin{array}{c}19 \\
43.18\end{array}$ \\
\hline & Transglottic & $\begin{array}{c}\text { Number of patients } \\
\text { Percentage }\end{array}$ & $\begin{array}{c}5 \\
11.36\end{array}$ \\
\hline
\end{tabular}

prevented tumor recurrence via inhibiting IL-10 production by TAMC [12]. Other authors implicated IL10 as a cytokine that might modify development/maturation of DC into a population expressing increased amounts of B7-2 co-molecule and capable of inducing tolerance [13].

Patients with advanced cancer including squamous cell carcinoma of the head and neck are known to be immunologically compromised $[14,15]$. Tumor cells can therefore escape from the immune responses by numerous mechanisms, including the molecule CD200 that acts as a potent suppressor of CD200Rexpressing immune cells [16-18]. CD200 molecule or its natural ligand play role in the delivery of a tolerance-inducing signal. Natural expression of CD200 was initially first described on thymic dendritic cells [19]. Further studies revealed that CD200 positive cells can inhibit the stimulation of type- 1 cytokine production by bone-marrow-derived B7-1 (and B7-2) positive dendritic cells [20]. Other data also implied an immunoregulatory role for CD200 expression, assayed by altered cytokine production in vitro from cells stimulated in the presence or absence of expressed CD200 [21], which has been nowadays widely accepted as the immunosuppressive factor. E.g., data presented by Gorczynski et al. [22] suggest that CD200 was functionally important in the increased graft survival of renal graft seen in portal venous peritransplant-immunized with dendritic cells from bone marrow cultures of mice receiving renal allografts. Increased expression of CD200 on dendritic cells was associated with the inhibition of cytokine production and renal allograft rejection. These authors also suggested that CD200 provides a costimulator signal for preferential IL-4 (TGF- $\beta$ ) production [20]. Borriello et al. [21] also reported that CD200 provided a costimulatory signal for activated murine $\mathrm{T}$ cells, but was unable to increase IL-2 production. 
Furthermore, Hoek et al. [16] suggested that binding of CD200 antigen with its specific receptor CD200R on myeloid cells such as macrophages, was responsible for down regulation of its activity, so the tissue damage caused by macrophages might be naturally reduced. Rosenblum et al. [24] found higher expressions of CD200 on dendritic cells that underwent apoptosis. The most recent study, provided by Seeds et al. [25] showed that CD200 knock-out macrophages produced more IFN- $\alpha$ than wild-type macrophages in response to stimulus, what was consistent with CD200's known inhibitory effect on myeloid cells. In contrast, blocking CD200 with an antiCD200 mAb resulted in reduced IFN $\alpha$ production. This suggests there could be a differential effect of CD200 on IFN induction pathways in dendritic cells and macrophages. These results support the hypothesis that CD200 is involved in virally induced type I IFN induction [25].

A number of monoclonal antibodies (mAbs) has been successfully used in the treatment of solid cancers. Because CD200 does not have a signaling domain it appears that anti-CD200 Abs do not directly affect targeted tumor cells, and Kretz-Rommel et al. [26] demonstrated that the anti-CD200 mAbs, as expected, did not inhibit tumor cell proliferation or directly induce cell death [27]. Therefore, antagonistic anti-CD200 Abs are expected to exert their effect by blocking immune suppression and by potentially mediating antibody-dependent cellular cytotoxicity or complement-dependent cytotoxicity. Presented studies demonstrated that a blockade of CD200 immune suppression by anti-CD200 mAb in the presence or absence of antibody effector function was sufficient to achieve high antitumor activity. Our data indicate that also dendritic cell based immunotherapy supported by the use of $\mathrm{mAb}$ anti-CD200 may be effective in the future treatment of laryngeal cancer, however, further studies analyzing the effects of both $\mathrm{mAb}$ antiCD200 and anti-CD200R, and Mo-DCs on autologous laryngeal cancer cell cultures have to be performed.

We showed that there was a relation between the presence of laryngeal cancer and the expression of CD200 and CD200R molecules on the CD83+ monocyte-derived dendritic cells pulsed with autologous cancer cell lysates. Unstimulated CD83 + Mo-DCs of laryngeal cancer patients and healthy controls presented significantly lower MFI values of CD200 and CD200R antigen expression than the same cell types from laryngeal cancer patients. It seems to be expedient to conduct an analysis which would assess the influence of these glycoproteins on the clinical course of the disease. The antibodies which are directed against
CD200 and CD200R molecules antigens can be applied in the treatment of laryngeal cancer to inhibit the immunosuppressive activity of CD200 molecule.

\section{Acknowledgements}

This study was supported by research grant No. N N403 088535 from the Polish National Science Center.

\section{References}

1. Barclay AN, Clark MJ, McCaughan GW. Neuronal/lymphoid membrane glycoprotein MRC OX-2 is a member of the immunoglobulin superfamily with a light-chain-like structure. Biochem Soc Symp. 1986;51:149-157.

2. McWhirter JR, Kretz-Rommel A, Saven A et al. Antibodies selected from combinatorial libraries block a tumor antigen that plays a key role in immunomodulation. Proc Natl Acad Sci USA. 2006;103:1041-1046.

3. Wright GJ, Jones M, Puklavec MJ, Brown MH, Barclay AN. The unusual distribution of the neuronal/lymphoid cell surface CD200 (OX2) glycoprotein is conserved in humans. Immunology. 2001;102:173-179.

4. Wong KK, Khatri I, Shaha S, Spaner DE, Gorczynski RM. The role of CD200 in immunity to B cell lymphoma. J Leukoc Biol. 2010;88:361-372.

5. Stumpfova M, Ratner D, Desciak EB, Eliezri YD, Owens DM. The immunosuppressive surface ligand CD200 augments the metastatic capacity of squamous cell carcinoma. Cancer Res. 2010;70:2962-2972.

6. Bień S, Kamiński B, Zyłka S, Mezyk R, Piasta Z. Evolution of the epidemiology and clinical characteristics of larynx and hypopharynx carcinoma in Poland from 1991 to 2001. Eur Arch Otorhinolaryngol. 2008;265:39-46.

7. Starska K, Głowacka E, Kulig A, Lewy-Trenda I, Bryś M, Lewkowicz P. The role of tumor cells in the modification of $\mathrm{T}$ lymphocytes activity - the expression of the early CD69(+), CD71(+) and the late CD25(+), CD26(+), HLA/ $\mathrm{DR}(+)$ activation markers on $\mathrm{T} \mathrm{CD} 4(+)$ and $\mathrm{CD} 8(+)$ cells in squamous cell laryngeal carcinoma. Part I. Folia Histochem Cytobiol. 2011;49:579-592.

8. Marioni G, Blandamura S, Loreggian L et al. Laryngeal carcinoma prognosis after postoperative radiotherapy correlates with CD105 expression, but not with angiogenin or EGFR expression. Eur Arch Otorhinolaryngol. 2011;268:1779-1787.

9. Sakakura K, Chikamatsu K, Takahashi K, Whiteside T, Furuya N. Maturation of circulating dendritic cells and imbalance of T-cell subsets in patients with squamous cell carcinoma of the head and neck. Cancer Immunol Immunother. 2006;55:151-159.

10. Fields RC, Shimizu K, Mulé JJ. Murine dendritic cells pulsed with whole tumor lysates mediate potent antitumor immune responses in vitro and in vivo. Proc Natl Acad Sci USA. 1998;95:9482-9487.

11. Asavaroengchai W, Kotera Y, Mulé JJ. Tumor lysate-pulsed dendritic cells can elicit an effective antitumor immune response during early lymphoid recovery. Proc Natl Acad Sci USA. 2002;99:931-936.

12. Wang L, Liu JQ, Talebian F, El-Omrani HY, Khattabi M, Yu L, Bai XF. Tumor expression of CD200 inhibits IL-10 production by tumor-associated myeloid cells and prevents tumor immune evasion of CTL therapy. Eur J Immunol. 2010;40:2569-2579. 
13. Steinbrink K, Wolfl M, Jonuleit H, Knop J, Enk AH. Induction of tolerance by IL-10-treated dendritic cells. J Immunol. 1997;159:4772-4780.

14. Hadden JW. The immunopharmacology of head and neck cancer: an update. Int J Immunopharmacol. 1997;11/12:629-644.

15. Richtsmeier WJ. Immunology of head and neck cancer. Bull Am Coll Surg. 1997;82:32-53.

16. Hoek RM, Ruuls SR, Murphy CA. Down-regulation of the macrophage lineage through interaction with OX2 (CD200). Science. 2000;290:1768-1771.

17. Wright GJ, Puklavec MJ, Willis AC. Lymphoid/neuronal cell surface OX2 glycoprotein recognizes a novel receptor on macrophages implicated in the control of their function. Immunity. 2000;13:233-242.

18. Gorczynski R, Chen Z, Kai Y, Lee L, Wong S, Marsden PA. CD200 is a ligand for all members of the CD200R family of immunoregulatory molecules.J Immunol. 2004;172:7744-7749.

19. Barclay AN. Different reticular elements in rat lymphoid tissue identified by localization of Ia, Thy- 1 and MRC OX-2 antigens. Immunology. 1981;44:72-77.

20. Gorczynski L, Chen Z, Hu J, Kai G, Ramakrishna V, Gorczynski RM. Evidence that an OX-2 positive cell can inhibit the stimulation of type- 1 cytokine production by bone-marrow-derived B7-1 (and B7-2) positive dendritic cells. J Immunol. 1999;162: 774-781.
21. Borriello F, Lederer J, Scott S, Sharpe AH. MRC OX-2 defines a novel $\mathrm{T}$ cell costimulatory pathway. J Immunol. 1997;158:45-49.

22. Gorczynski RM, Chen Z, Fu XM, Zeng H. Increased expression of the novel molecule OX-2 is involved in prolongation of murine renal allograft survival. Transplantation. 1998;65:1106-1114.

23. Gorczynski RM, Chen Z, Yu K. CD200 immunoadhesin suppresses collagen-induced arthritis in mice. Clin Immunol. 2001;101:328-334.

24. Rosenblum MD, Olasz E, Woodliff JE. CD200 is a novel p53target gene involved in apoptosis-associated immune tolerance. Blood. 2004;103:2691-2698.

25. Seeds RE, Mukhopadhyay S, Jones IM, Gordon S, Miller $\mathrm{JL}$. The role of myeloid receptors on murine plasmacytoid dendritic cells in induction of type I interferon. Int Immunopharmacol. 2011;11:794-801.

26. Kretz-Rommel A, Qin F, Dakappagari N, Cofiell R, Faas SJ, Bowdish KS. Blockade of CD200 in the presence or absence of antibody effector function: implications for anti-CD200 therapy. J Immunol. 2008;180:699-705.

27. Kretz-Rommel A, Qin F, Dakappagari N et al. CD200 expression on tumor cells suppresses antitumor immunity: new approaches to cancer immunotherapy. J Immunol. 2007; 178:5595-5605.

Submitted: 8 February, 2012

Accepted after reviews: 11 February, 2013 